\title{
HEALTH HAZARD AFTER NATURAL DISASTERS IN BANGLADESH
}

UDDIN $\mathrm{KN}^{*}$

\begin{abstract}
A natural disaster is defined as an event of nature, which overwhelms local resources and threatens the function and safety of the community. Our main natural disasters are related to Flood and torrential rain and related events.. Earth quake even tsunamis happened here but so far not to the devastating state. Technological disaster like collapse of big building unnoticed firebreak out in huge industry has claimed life here and risked prevailing health system. Volcanic eruptions, Wildfire, Wind/Snow storm are problem in other part of the world.

Deaths associated with natural disasters, particularly rapid-onset disasters, are overwhelmingly due to blunt trauma, crush-related injuries, or drowning. The relationship between natural disasters and communicable diseases is frequently misconstrued. The risk for outbreaks is often presumed to be very high in the chaos that follows natural disasters, a fear likely derived from a perceived misconception of association between dead bodies and epidemics. The availability of safe water and sanitation facilities, the degree of crowding, the underlying health status of the population, and the availability of healthcare services all interact within the context of the local disease ecology to influence the risk for communicable diseases and death in the affected population.

This review is prepared from research and review articles published in different journal.ECHO factsheet -2017. WHO technical reports, CDC fact sheet,Pan Am health organization report werealso studied.

A public health approach to disaster risk managementshould focus on decreasing the vulnerability of communitiesthrough prevention and mitigation measures and increasingthe coping capacity and preparedness of the health sectorand community
\end{abstract}

Keywords: Disasters, epidemics, riskfactors, communicable diseases

\section{Introduction:}

Disasters are generally classified according to the immediate trigger of the event:

- Natural disasters, where the trigger is a natural phenomenon or hazard (biological, geological, orclimatic)viz-cyclone;

- Technological disasters, such as chemical spills; or

- Complex emergencies, such as civil wars andconflicts. Natural disasters again can be split in three categories: hydro-meteorological disasters, geophysical disasters and geomorphologic disasters.

\section{Natural disasters}

a) Hydro-meteorological disasters, like floods, are the most common (40 percent) natural disasters $s$ of Bangladesh and worldwide.

b) Geophysical disasters are the second-most reported type of natural disaster, and earthquakes are the majority of disasters in this category. Tsunamis are commonly associated with earthquakes, , they have a similar clinical and threat profile (water-related consequences) to that of tropical cyclones (e.g., typhoon or hurricane).

c) Geomorphologic disasters, such as avalanches and landslides, also are associated with infectious disease transmissions and outbreaks, but documentation is generally lacking.

Address of Correspondence: Prof. Khwaja Nazim Uddin MBBS FCPS FACP FRCP, Professor of Medicine Ibrahim Medical College \& Birdem academy. Hon Senior Consultant, Birdem General Hospital. E-mail: knuddin61@gmail.com

Bangladesh J Medicine 2017; $28: 81-90$ 
Deadly (deadliest ever!) mudslide triggered by torrential monsoon rain in southeastern Bangladesh in recent days (June 2017) have claimed 135 lives .It happened just two weeks after the Cyclone Mora May 2017(previously Cyclone Bhola 1970,Gorky 1991,Sidr 2007,Aila 2009, Roanu 2016). Renewedmudslides, collapsing hillsides and heavy flooding estimated to have cause further damage (UN RC Jun 2017).

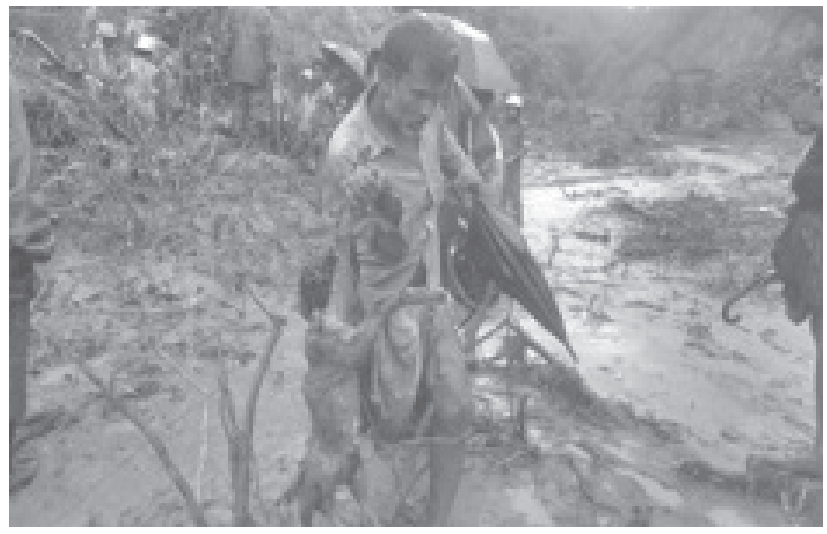

\section{Mudslides and rescue effort}

Bangladesh experience different type of natural disasters almost every year because of global warming and change of climate. Almost $80 \%$ of total area of the country is prone to floods / flash flood. Southand south-eastern part of the country were hit by cyclone and storm surges during last few years. Whole coastal belt along Bay of Bengal is experiencing salinity intrusion. Whereas north and north western part of the country are experiencing extreme temperature and Drought almost every year Drought

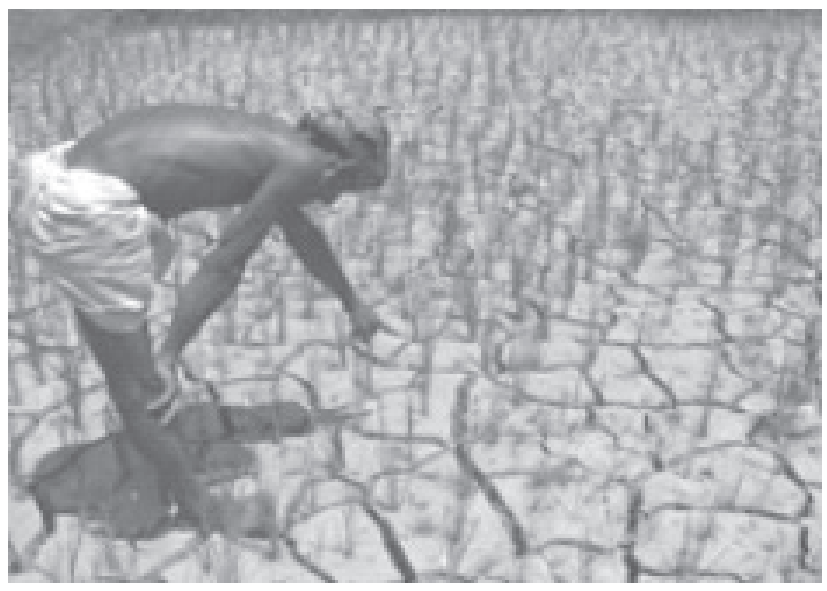

Dead Bodies and Disease

The sudden presence of large numbers of dead bodies in the disaster-affected area may heighten concerns of disease outbreaks ${ }^{1}$ despite the absence of evidence that dead bodies pose a risk for epidemics after natural disasters. Dead bodies only pose health risks in a few situations that require specific precautions, such as deaths from cholera or hemorrhagic fevers

\section{The Immediate Effects of Natural Disasters - Direct effect}

Every disaster scenario is unique in its own way ${ }^{2}$ .Itis crucial, however, to be conscious that injury types are not exclusive to any one situation. As a basis for planning, it is nevertheless useful to consider the types of injuries the majority of the victims will incur in order to evaluate the immediate needs of the disaster response team.

\section{Earthquakes/Collapse of large building}

Earthquakes induce a high level of mortality due to crush injuries from falling objects.

If an earthquake occurs at night, there is a greater incidence of trauma to the pelvis, thorax, and spine.. Theseinjuries commonly lead to severe damage to internal organs coinciding with severe internalbleeding. If the earthquake occurs during the daytime, it is more common to see injuries of theextremities with comorbid lacerations, severe external bleeding, and crush injuries including rhabdomyolysis and compartment syndrome. Injuries during a diurnal earthquake occur to the skull and the collarbonebecause of falling debris. ${ }^{3}$ Victims that have been trapped in fallen rubble for hours or possibly days run the risk of havinginfected wounds and/or gangrene. Common trauma procedures that need to be urgentlyaddressed include amputations, vascular stabilization, faciotomies, orthopedic stabilization, anddebridement and/or dressing of severe open wounds. It is important to note that patients whosuffer from crush injuries also run a high risk of developing hypovolemic shock, hyperkalemia, renal failure, and have a greater chance of having a fatal cardiac arrhythmia or myocardialinfarct. ${ }^{4}$ Fire is another major concern within the first 'golden' 24 hours after thedisaster. , burn injuries, as well as respiratoryproblems due to smoke inhalation can quickly become a major strain on the medical system after an earthquake or sudden collapse of a large building.

Outbreaks of infectious diseases may be reported when earthquake disasters result in substantial population displacement into unplanned and overcrowded shelters, the destruction of water/ sanitation systems and the degradation of sanitary conditions directly caused by the earthquake. 
Tsunamis: are catastrophic tidal waves caused by earthquakes on the ocean floor. Waves can travel several hundredkilometers per hour and can be as much as 10 meters high when they reach shore. Tsunamis are commonly associated with earthquakes, they have a similar clinical and threat profile (water-related consequences) to that of tropical cyclones (e.g., typhoon or hurricane).Damage on shore can be extensive, and usually the number of deaths far exceeds the number of survivors with severe injuries

\section{Droughts}

In a region that has been severely affected by adrought, mortality may increase sharply due to protein malnutrition (kwashiorkor) or calorie malnutrition (marasmus). Certain vitamin deficiencies, such as a lack of Vitamin A, can lead tospecific consequences such as xerpohthalmia and child blindness. Long standing malnutritioncan easily lead to increased rates of disease and mortality, and limit the general population'sfunctionality.

\section{Floods/Climate disasters}

Include seasonal floods, hurricanes, andtyphoons. Seasonal floods cause increased incidence of diarrheal diseases, respiratory infections, dermatitis, andsnake bites. The risk of compromised water supplies dependson the condition of the community's water supply before thedisaster.

The greatest risk of mortality from a flood is predictably drowning. In our place floodsaccount for more yearly deaths than all other natural disasters. It takes less than two feet of moving water to float a large vehicle such as aschool bus, and only between three and six inches of fast moving water to sweep a large man off his feet. ${ }^{5}$

Second only to drowning, exposure to different elements accounts for a large percentage of the deaths and critical injuries that occur in flood.

The public health consequences of flooding are disease outbreaks mostly resulting from the displacement of people into overcrowded camps and cross-contamination of water sources with fecal material and toxic chemicals. Flooding also is usually followed by the proliferation of mosquitoes, resulting in an upsurgence of mosquito-borne diseases such as malaria. Documentation of disease outbreaks and the public health after-effects of tropical cyclones (hurricanes and typhoons) and tornadoes, however, is lacking

\section{Hurricanes, Typhoons, and Cyclones}

In a hurricane (cyclones in the Indian Ocean and typhoons in the western Pacific Ocean), the greatest mortality originates from the secondary disasters that have been triggered such as small tornadoes, flash flooding, and storm surges. In coastal regions (within 30 miles of a salt-water coast), the level of a hurricane's storm surge is one of the strongest predictors of mortality. Historically, nine out of ten deaths form a hurricane can be directly accounted to the preceding storm surge. This effect can be exacerbated by superimposing wind waves upon the storm tidal height and the strong winds. Crush injuries are common in severe storms. In a hurricane, many additional trauma incidents are caused by large objects which can become Airborne in the severe winds. The most common non- fatal traumatic injury in a hurricane is superficial lacerations from flying glass and other debris. ${ }^{6}$

\section{Tornadoes}

Due to the lack of warning, a tornado offers a community little time to prepare or seek shelter, and hence the morbidity and mortality is proportionally higher compared to other disasters. ${ }^{15}$ In the United States, the leading cause of death and critical permanent injury in a tornado is cranio-cerebral injury due to projectiles accelerated by tornado winds. Crush injuries due to .collapsing structures or extremely large airborne debris are also frequent. Lacerations, contusions, abrasions, punctures, and musculoskeletal strain account for over half of the total injuries seen in local emergency rooms. Most victims suffer from multiple wounds and many of the soft tissue injuries occur in areas of exposed skin such as the head and neck. Tornado victims also exhibit a characteristic abrasion pattern on exposed skin that is due to fine particles of soil, mud, sand, and even water which strike the body at highly accelerated speeds. ${ }^{8}$

Wound contamination, and subsequent infection, appear to be a major contributor to post operative sepsis leading to an increased need of aggressive wound care and surgical debridement. One fifth of fracture injuries in the aftermath of a tornado can be expected to be open, contributing to the infection rates among patients.

\section{Mudslides/avalanches/landslide}

Mudslides, which are commonly seen inflooding situations as well, can lead to crush injuries, severe internal bleeding, multiple organdysfunction syndrome, and asphyxiation In many instances mudslides occur in conjunction with volcanic eruptions as the topographical contour of the hillside is changed rapidly. 


\section{Fire:}

Bush fire or wild fire is not common in our place.However, large-scale urban fires are still Possible so also those secondary to other natural disasters like earthquake and those of technological disaster like industrioal fire and fire after a collapse of a large building with huge dwellers/workers. Injuries in a large-scale urban fire are more commonly burn injuries and deaths associated with asphyxiation. Common complications of burn injuries include hypovolemic shock as well as massive infection and sepsis.

\section{Immediate -Indirect Medical Consequences of Natural Disasters \\ Cardiometabolic}

a) Cardiacevents:In the aftermath of a major natural disaster such as an earthquake where structural damage is common, an increase in acute myocardial infarctions (AMI) is not uncommon. ${ }^{9}$ In the Taiwan Chi-Chi Earthquake of 1999, the sudden increase of heart attacks were limited to mostly male patients and was attributed mainly to formerly sedentary individuals becoming suddenly and intensely active throughout the rescue period. ${ }^{10}$ It has also been suggested that the physiological 'fight or flight' response that is initiated during times of perceived personal danger such as an earthquake or other natural disaster, is itself contributory to the increase of post catastrophe AMIs. The fight or flight response, which is a hallmark of systemic sympathetic nervous system activation, leads to an increased vulnerability to myocardial attacks in individuals with pre-existing heart disease. ${ }^{10}$ Along with outright heart attacks, other cardiovascular complications are increasingly seen after natural disasters such as unstable angina and potentially fatal arrhythmias.

b) Others:In many instances, the affect of the increased stress load is compounded with the interruption of regular medical services for preexisting conditions such as Diabetes Mellitus and high Cholesterol.

RA: One study of rheumatoid arthritis (RA) patients showed that a fter an earthquake the incidence of RA activity (pain, stiffness, and swelling) increased dramatically. ${ }^{11}$

\section{Respiratory Problems:}

In some instances, respiratory conditions such as allergies and asthma are aggravated after a natural disaster. This is especially true if there has been large-scale ejection of pollutants into the atmosphere as with a volcanic eruption or forest fire .In many studies, there was little to no appearance of de novo respiratoryconditions among the general population who received minimal to medium amount of exposure to the airborne irritants. , respiratory illnesses start to show a substantial increase in the days to weeks after a disaster. This apparent shift in illness is attributed more to the transmission of communicable diseases such as influenza or even tuberculosis in crowdedtemporary shelters. Likewise, respiratory illnesses have been noted to particularly increase in the extended aftermath of a flood. As the floodwater recedes and victims reclaim their former livingareas, the concentration of allergens such as dust mites climb dramatically within washed out homes, schools, and offices. ${ }^{12}$

\section{Infections:}

The risk factors for increased infectious diseases transmission and outbreaks are mainly associated with the after-effects of the disasters rather than to the primary disaster itself or to the corpses of those killed.

\section{Diarrheal diseases}

Diarrheal diseases cause over 40 percent of the deaths in disaster and refugee camp settings. Epidemics among victims are commonly related to polluted water sources (faecal contamination), or contamination of water during transportation and storage. Outbreaks have also been related to shared water containers and cooking pots, scarcity of soap and contaminated food, as well as pre-existing poor sanitary infrastructures, water supply and sewerage systems.Diarrhoeal epidemics are frequently reported following natural disasters in developing countries like us. Floods are recurrent in many countries like Bangladesh.and usually lead to a significant increase in diarrheal disease incidences. Following the 2005 earthquake in Pakistan, an estimated 42 percent increase in diarrheal infections was reported. In Iran, 1.6 percent of the 75,586 persons displaced by the Bam earthquake in 2003 were infected with diarrhoeal diseases. A rapid assessment conducted in Indonesia after the 2004 tsunami showed that 85 percent of the survivors in the town of Calang experienced diarrheal illness after drinking from contaminated wells.An investigation conducted in 100 households after the 2001 earthquake in El Salvador showed that 137 persons out of 594 (22 percent) experienced diarrheal infections. An evolving cholera epidemic was reported 9 months after the earthquake in Haiti, with a high fatality rate of 6.4 percent among the victims (of the 4,722 documented affected, 303 died).".Though public health officials used to live by the rule that if a disease wasn't in a community before the disaster 
it wouldn't be there after, they have come to find that like every rule, there are exceptions.In Haiti after the disastrous(Haiti suffered from a 7.0 earthquake in January 2010) earthquake it happened. Then in October 2010 a cholera epidemic broke out. Later it was discovered the disease was brought over by foreign aid workers.. "In Haiti, where they had not had cholera in 100 years, new imported cases caused an outbreak

Only a small cluster of Norovirus cases was reported in evacuation centers some weeks after the Great Eastern Japanese Earthquake and tsunami, while various pathogens were confirmed among the populations displaced by Hurricanes Allison (2001) and Katrina in the US.

\section{Diseases Associated with Crowding}

Measles- Crowded living conditions facilitate measles transmission. The risk for transmission after a natural disaster are dependent on baseline immunization coverage among the affected population, and in particular among children $<15$ years of age and necessitate even higher immunization coverage levels to prevent outbreaks ${ }^{5}$ A measles outbreak in the Philippines in 1991 among persons displaced by the eruption of Mt. Pinatubo involved $>18,000$ cases ${ }^{13}$.After the tsunami in Aceh, a cluster of measles involving 35 cases occurred in Aceh Utara district, and continuing sporadic cases and clusters were common despite mass vaccination campaigns ${ }^{14}$.In Pakistan, after the 2005 South Asia earthquake, sporadic cases and clusters of measles (>400 clinical cases in the 6 months after the earthquake) also occurred .

Neisseria meningitidis meningitis is transmitted from person to person, particularly in situations of crowding. Cases and deaths from meningitis among those displaced in Aceh and Pakistan have been documented ${ }^{15}$. Prompt response with antimicrobial prophylaxis, as occurred in Aceh and Pakistan, can interrupt transmission..

ARI-Acute respiratory infections (ARI) are a major cause of illness and death among displaced populations, particularly in children $<5$ years of age... The reported incidence of ARI increased 4-fold in Nicaragua in the 30 days after Hurricane Mitch in $1998^{7}$ and ARI accounted for the highest number of cases and deaths among those displaced by the tsunami in Aceh in $2004^{15}$ and by the 2005 earthquake in Pakistan

Other Diseases Associated with Natural Disasters

Tetanus: Contaminated wounds, particularly in populations where vaccination coverage levels are low, are associated with illness and death from tetanus. A cluster of 106 cases of tetanus, including 20 deaths, occurred in Aceh and peaked 2-1/2 weeks after the tsunami ${ }^{3}$ Cases were also reported in Pakistan following the 2005 earthquake. ${ }^{16 .}$

Fungal infections: An unusual outbreak of coccidiomycosis occurred after the January 1994 Southern California earthquake. It is caused by the fungus Coccidioidesimmitis, which is found in soil in certain semiarid areas of North and South America. This outbreak was associated with exposure to increased levels of airborne dust subsequent to landslides in the aftermath of the earthquake. ${ }^{17}$

Phases of outbreak and classification of infectious disease

Three clinical phases of natural disasters summarize the chronological public health effects on injured people and survivors:

- $\quad$ Phase (1), the impact phase (lasting up to to 4 days), is usually the period when victims are extricated and initial treatment of disasterrelated injuries is provided.

- $\quad$ Phase (2), the post-impact phase (4 days to 4 weeks), is the period when the first waves of infectious diseases (air-borne, food-borne, and/ or water-borne infections) might emerge.

- $\quad$ Phase (3), the recovery phase (after 4 weeks), is the period when symptoms of victims who have contracted infections with long incubation periods or those with latent-type infections may become clinically apparent. During this period, infectious diseases that are already endemic in the area, as well as newly imported ones among the affected community, may grow into an epidemic.

Short term effect of disaster a)The Rescue Stage - Disruption of The Initial Emergency Response

Within the first 24 hours the focus must remain on ensuring that the most critically ill and accessible patients receive the appropriate medical attention and care.in the worst case scenario, the very core of the health infrastructure, the hospital, could bedisrupted. A review of many of the recent major natural disasters in United States revealed thatdamage or collapse of a hospital is quite rare. There may be damage to emergency vehicles roads(transport), medical supply depots and storage facilities and number of victims may overwhelm themedical system's ability to provide for everyone so also the loss of medical personnel. 
A prevailing assumption is that a department may double or even triple their available work force by activating "off-duty/off shift"personnel. In large-scale disasters however this is not necessarily the case.

b) the rescue stage - disruption of the infrastructure critical to Public health and welfare: The critical infrastructure constitutes a variety of systems including shelter, power grids, fuel lines, the supply of potable water, transportation networks, and communication systems. Disruption of these services can have immediate effects, as well as long-term consequences.

c) the recovery stage- short term and long term public health Concerns After a catastrophe, as days turn to weeks, the rescue period gradually transforms into the recovery and reconstruction period.

The most pressing public health concernsinclude quickly establishing adequate hygiene protocols, controlling the outbreak of endemicdiseases, and reestablishing routine health activities. One of the primary goals of local health officials in the wake of a major disaster is to resume thenormal health practices of the region.Diseases thatcommonly affect shelters include influenza, measles, whooping cough, tuberculosis, and scabiesand other skin infections..

\section{Common misconceptions of disaster response and effect on Health}

Assistance needed: It is a common misconception in the aftermath of a disaster is that any and all medical assistance is needed immediately.It has been observed that the local population is largely capable of providing initial rescue needs. ${ }^{18}$ It is thus importantfor disaster stricken areas to quickly and concisely request what medical services and aid isneeded. Common inappropriate medical assistance include medications unsuitable for traumacare, generally trained health workers unfamiliar with the special needs of disaster victims, andextremely subspecialized surgical teams whose skills are applicable only to a small patient load.

Rumors:In the aftermath of a large scale natural disaster, rumors quickly abound regarding epidemics ofuncommon and exotic diseases. While it is true that poor sanitary conditions and inadequatepersonal hygiene increases the risk of illness, post disaster epidemics occur only if the pathogensare common to the local area. Despite frequent media coverage of widespread looting after a large disaster with dazed andconfused victims, studies show that individuals rarely panic or engage in anti-social behavior. Observation reveals that in many different cultures, survivors of a major catastrophe are ableto quickly organize into community groups in order to actively participate in the rescue phase.

\section{Long-Term Impacts of disasters:}

a)Health Service System(Infrastruture). The real damage in the long run is done to "the health service infrastructure. "Earthquakes tremor to stillness, tsunamis subside, and flood waters recede. But the effects ripple long after the actual eventwhich has been referredto as "chronic emergencies."

The prolonged health impact of natural disasters on a community may be the consequence of the collapse of health facilities and healthcare systems, the disruption of surveillance and health programs (immunization and vector control programs), the limitation or destruction of farming activities (scarcity of food/food insecurity), or the interruption of ongoing treatments

These after-effects include displacement of populations (internally displaced persons and refugees), environmental changes and increased vector breeding sites. Unplanned and overcrowded shelters, poor water and sanitation conditions, poor nutritional status or insufficient personal hygiene are often the case. Power cuts related to disasters may disrupt water treatment and supply plants, thereby increasing the risk for waterborne diseases. Lack of power may also affect proper functioning of health facilities, including preservation of the vaccine cold chain. An increase in diarrheal illness in New York City followed a massive power outage in 2003.

b)The long-term health conditions:

Typically addressed during the redevelopment phase include mental and psychological issues, vaccinating and eliminating the outbreak of communicable diseases like cholera, malaria, and measles and reinstating the infrastructure of the health services system

1. Mental healthdisorders:. In the weeks and months following a disaster event, many patients will suffer from such psychological disorders such as post-traumatic stress disorder (PTSD) or general anxiety disorder (GAD. ${ }^{19}$ In many instances victims and survivors complain of some of the following symptoms: night terrors, sudden phobias, grief, depression, guilt, insomnia, loss of appetite or flashbacks and hallucinations. It is common for many behavioral responses - to disasters and catastrophic events - to remain subtly buried within a victim's coping mechanisms, surfacing only under close observation of key health related habits such as sleeping, eating, smoking, or alcohol consumption 
Mental health problems rarely manifest themselves in the early stages of the emergency"But then you hope and expect to see people returning to some kind of normalcy; picking up and trying to dig out and get themselves into their houses and back to school or back to work. And when that doesn't happen then that's a sign the individual is beginning to experience post-traumatic stress disorder, maybe depression, or maybe anxiety."

It is for this reason health professionals urge people in natural disaster ridden communities to return to their daily routines as soon as possible.

\section{Communicable Diseases}

Communities reeling from natural disasters also tend to become breeding grounds for outbreaks of communicable diseases, which are defined as diseases that easily transfer from person to person or animal to person. "Continuing problems with hygiene and diseases related to hygiene are common in refugee camps,"

Water-related Communicable Diseases

\section{Waterborne disease:}

a)Diarrheal disease outbreaks can occur after drinking water has been contaminated. An outbreak of diarrheal disease after flooding in Bangladesh in 2004 involved $>17,000$ cases; Vibrio cholerae $(01$ Ogawa and $\mathrm{O} 1 \mathrm{Inaba}$ ) and enterotoxigenic Escherichia coli were isolated. ${ }^{20}$ A large ( $>16,000$ cases) cholera epidemic (O1 Ogawa) in West Bengal in 1998 was attributed to preceding floods and floods in Mozambique in January-March 2000 led to an increase in the incidence of diarrhea.

In Indonesia in 1992-1993, flooding was identified as a significant risk factor for diarrheal illnesses caused by Salmonella enterica serotype Paratyphi A (paratyphoid fever. ${ }^{21}$ In a separate evaluation of risk factors for infection with Cryptosporidium parvum in Indonesia in 2001-2003, case-patients were $>4 \times$ more likely than controls to have been exposed to flooding.

b) Hepatitis: In hepatitis E-endemic areas, outbreaks frequently follow heavy rains and floods; the illness is generally mild and self-limited, but in pregnant women case-fatality rates can reach 25\%). After the 2005 earthquake in Pakistan over 1,200 cases of acute jaundice, many confirmed as hepatitis E, occurred among the displaced. 22 Clusters of both hepatitis A and hepatitis E were noted in Aceh after the December 2004 tsunami .

c) leptospirosis::Outbreaks of leptospirosis occurred in Taiwan, Republic of China, associated with Typhoon Nali in 2001; in Mumbai, India, after flooding in 2000);23 in Argentina after flooding in 1998); and in the Krasnodar region of the Russian Federation in 1997 .

\section{Vector borne Diseases}

Natural disasters, particularly meteorological events such as cyclones, hurricanes, and flooding, can affect vector-breeding sites and vector borne disease transmission. While initial flooding may wash away existing mosquito-breeding sites, standing water caused by heavy rainfall or overflow of rivers can create new breeding sites. This situation can result (with typically some weeks' delay) in an increase of the vector population and potential for disease transmission, depending on the local mosquito vector species and its preferred habitat. The crowding of infected and susceptible hosts, a weakened public health infrastructure, and interruptions of ongoing control programs are all risk factors for vector borne disease transmission. ${ }^{24}$

Malaria outbreaks in the wake of flooding are a wellknown phenomenon. An earthquake in Costa Rica's Atlantic Region in 1991 was associated with changes in habitat that were beneficial for breeding and preceded an extreme rise in malaria cases. Additionally, periodic flooding linked to El NiñoSouthern Oscillation has been associated with malaria epidemics in the dry coastal region of northern Peru.

Dengue transmission is influenced by meteorological conditions, including rainfall and humidity, and often exhibits strong seasonality. ${ }^{25}$ However, transmission is not directly associated with flooding. Such events may coincide with periods of high risk for transmission and may be exacerbated by increased availability of the vector's breeding sites (mostly artificial containers) caused by disruption of basic water supply and solid waste disposal services. The risk for outbreaks can be influenced by other complicating factors, such as changes in human behavior (increased exposure to mosquitoes while sleeping outside, movement from dengue-nonendemic to endemic areas, a pause in disease control activities, overcrowding) or changes in the habitat that promote mosquito breeding (landslide, deforestation, river damming, and rerouting of water).

Although it is not possible to predict with accuracy which diseases will occur following certain types of disasters, diseases can be distinguished as either water-borne, air-borne/droplet or vector-borne diseases, and contamination from wounded injuries. The following table shows a breakdown of the occurrence of communicable diseases. 
Risk factors and onset of communicable diseases following natural disasters

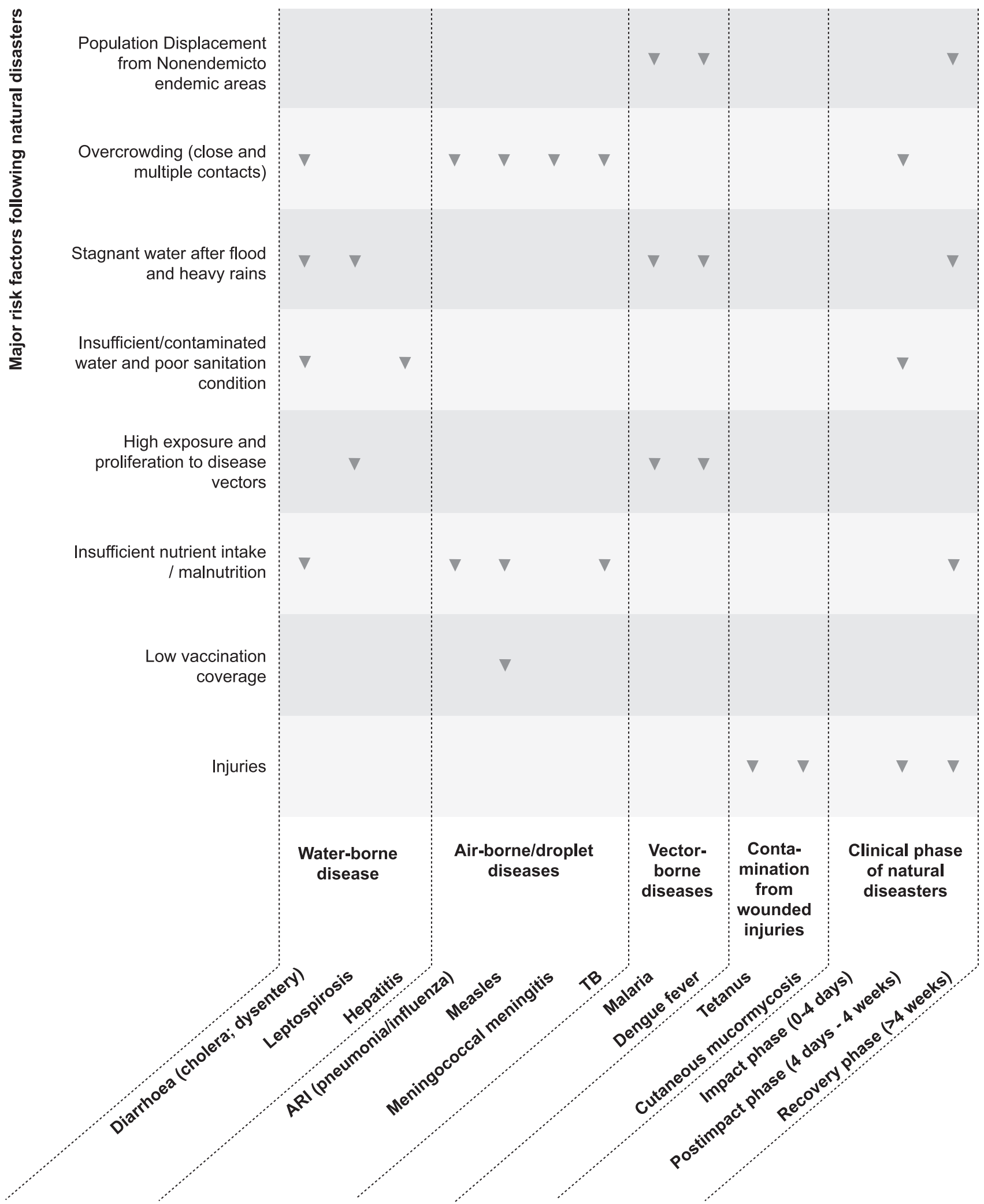

**https: / / unu.edu/publications / articles / preventing-and-controlling-infectious-diseases-after naturaldisasters.html\#info 
Disaster Response: MITIGATION,prevention of diseases.

Effective treatment of mass casualties depends on local preparedness and requires triage of patients totreat those most likely to benefit first.

In disaster research and analysis, the vulnerability of a community is defined as the

"characteristics of a person or group in terms of their capacity to anticipate, cope with, resist, and

recover from the impact of a natural hazard", a society must establish and adequately practice a "Health Disaster Management Program". 26\% of our populations are affected by cyclone and $80 \%$ live in flood prone regions. Mortality and morbidity from these events have fallen substantially in the last 50 years, partially because of improvement of disaster management. Ministry of Disaster management and relief (MoDMR) formulated the $7^{\text {th }}$ five year $(2016-$ 2021) plan of climate change and disaster management.

An effective disaster mitigation program must include aspects of public education, professionaltraining, and multi-discipline collaboration and a systematic and comprehensive evaluation should identify 1) endemic and epidemic diseases that are common in the affected area; 2) living conditions of the affected population, including number, size, location, and density of settlements; 3) availability of safe water and adequate sanitation facilities; 4) underlying nutritional status and immunization coverage among the population; and 5) degree of access to healthcare and to effective case management.Disease control programs that were in operation before the disaster must continue.. Vector control programs are the single most effective method of controlling diseases such asmalaria, while vaccination programs are extremely effective for preventing outbreaks of illnessessuch as measles, whopping cough, and poliomyelitis.

Personal hygienemaintenance, sanitary education isneeded to ensure that victims properly dispose of refuse, maintain the cleanliness of temporaryshelters, and do not waste or contaminate potable water.Consideration must be given to removing preferential vector breeding grounds, such as stagnantwater, that are in close contact with population concentrations

\section{Conclusion}

Historically, fears of major disease outbreaks in the aftermath of natural disasters have shaped the perceptions of the public and policymakers. These expectations, misinformed by associations of disease with dead bodies, can create fear and panic in the affected population and lead to confusion in the media and elsewhere.

The risk for outbreaks after natural disasters is low, particularly when the disaster does not result in substantial population displacement. Five (5) prioritymeasures that can reduce the risk for communicable disease transmission in populations affected by natural disasters are 1 . Safe water, sanitation, site planning.2. Primary healthcare services3. Surveillance/early warning system4.Immunization5. Prevention of malaria and dengue (Available from https://www.who.int/ medicines / publications / mrhealthkit.pdf)

\section{References:}

1. Epidemics caused by dead bodies.de Ville de Goyet C: a disaster myth that does not want to die. Rev PanamSaludPublica 2004;15:297-99

2. Negligible risk for epidemics after geophysical disasters.Floret N, Viel J-F, Mauny F, Hoen B, Piarroux R .Emerg Infect Dis 2006;12:543-48.

3. GIS Mapping of Earthquake-Related Deaths and Hospital Admissions from the 1994 Northridge, California, Earthquake.Peek-Asa, C. , Annals of Epidemiology2000;10(1): 5-13

4. Medical and Public Health Consequences of Natural and Biological Disasters. Eric K. Noji.Natural Hazards Review2003;2(3): 143-56.

5. Weather Basics - Why Flood Waters Are So Dangerous - USA Today. Article date: February 15, 2001 ,http: / / www.usatoday.com/weather/tg/ wfldangr/wfldangr.htm, Viewed on Jun 20,2017.

6. Center for Disease Control Website - National Center for Environmental Health-Hurricane - A prevention guide to promote your personal health and safety http: / / md.skolar.com/index_-.jsp?trg=\% 2 Fshine\% 2Fhome\%2Fsearch.jsp\&nav=home

7. Natural Disasters - Protecting the Public Health's .Pan American Health Organization, 2000 8The Medical Impact of Tornadoes in North America Bohonos, J.J., Hogan, D.E., The Journal of Emergency Medicine 1999; 19( 1):67 - 73

9. Increased acute myocardial infarction mortality following the 1995 Great Hanshin-Awaji earthquake in Japan.Ogawa K, Tsuji I, Shono K, Hisamichi S., Int J Epidemiol 2000 ; 29 (3): 449-55.

10. Derangement of heart rate variability during a catastrophic earthquake: a possible mechanism for increased heart attacks.Lin LY, Wu CC, Liu YB, Ho YL, Liau CS, Lee YT. Pacing ClinElectrophysiol 2001;24:1596-601 
BJM Vol. 28 No. 2

11. The Impact of Hurricane Hugo and the San Fransico Earthquake on a Sample of People with Rheumatoid Arthritis. Grady KE, Reisine ST, Fifield J, Lee NR, McVay J, Kelsey ME., Arthritis Care Res 1991 ;4(2):106-10.

12. Dust-mite-allergen concentrations in asthmatics' bedrooms in the Quad Cities (Illinois, USA) after the Mississippi River floods of 1993.Curtis L, Ross M, Scheff P, Persky V, Wadden R, Ramakrishnan V, HryhorczukD.Allergy 1997 ;52:642-49

13. Surveillance in evacuation camps after the eruption of Mt. Pinatubo, Philippines.Surmieda MR, Lopez JM, Abad-Viola G, Miranda ME, Abellanosa IP, Sadang RA, et al.. MMWR CDC SurveillSumm 1992;41:963

14. Measles transmission and vaccine effectiveness during a large outbreak on a densely populated island: implications for vaccination policy. Marin M, Nguyen HQ, Langidrik JR, Edwards R, Briand K, Papania MJ, et al.. Clin Infect Dis 2006; 42:31519

15. World Health Organization Epidemic-prone disease surveillance and response after the tsunami in Aceh Province, Indonesia. WklyEpidemiol Rec 2005; 80:160-64

16. World Health Organization Epidemic-prone disease surveillance and response after the tsunami in Aceh Province, Indonesia. WklyEpidemiol Rec 2005;80:160-64.

17. A coccidiomycosis outbreak following the Northridge, Calif, earthquake.Schneider E, Hajjeh
Health Hazard after Natural Disasters in Bangladesh

RA, Spiegel RA, Jibson RW, Harp EL, Marshall GA, et al. JAMA 1997;277:904-908

18. Coping with Natural Disasters: The Role of Local Health Personnel and The Community.Geneva : World Health Organization, 1989.

19. When Disasters and Age Collide: Reviewing Vulnerability of the Elderly. Ehren B. Ngo, Natural Hazards Review 2000; 2(2): 80-89.

20. EnterotoxigenicEscherichia coli and Vibrio cholerae diarrhea, Bangladesh. Qadri F, Khan AI, Faruque ASG, Begum YA, Chowdhury F, Nair GB, et al.Emerg Infect Dis 2005;11:1104-1107.

21. Risk factors for typhoid and paratyphoid fever in Jakarta, Indonesia.Vollaard AM, Ali S, van Asten HA, Widjaja S, Visser LG, Surjadi C, et al. JAMA 2004; 291:2607-15

22. Hepatitis E: an overview and recent advances in clinical and laboratory research. Aggarwal R, Krawczynski K. J GastroenterolHepatol 2000;15:920

23. An observational study to detect leptospirosis in Mumbai, India after flooding 2000. Karande S, Bhatt M, Kelkar A, Kulkarni M, De A, Varaiya A. Arch Dis Child 2003;88:1070-75

24. The E1 Nino southern oscillation and malaria epidemics in South America. Gagnon AS, SmoyerTomic KE, Bush AB.Int J Biometeorol 2002;46:8189.

25. Lifson AR. Mosquitoes, models, and dengue. Lancet 1996;347:1201-1202 